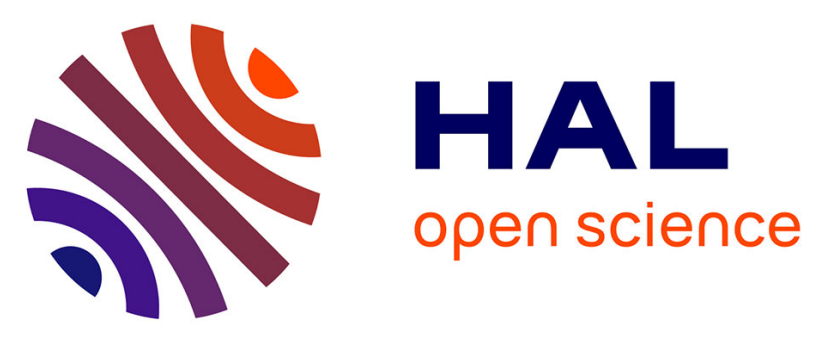

\title{
Coupling of X-ray computed tomography and surface in situ analysis combined with digital image correlation method to study low cycle fatigue damage micromechanisms in lost foam casting A319 alloy
}

Long Wang, Nathalie Limodin, Ahmed El Bartali, Eric Charkaluk

\section{To cite this version:}

Long Wang, Nathalie Limodin, Ahmed El Bartali, Eric Charkaluk. Coupling of X-ray computed tomography and surface in situ analysis combined with digital image correlation method to study low cycle fatigue damage micromechanisms in lost foam casting A319 alloy. Fatigue and Fracture of Engineering Materials and Structures, 2021, 44 (4), pp.916-932. 10.1111/ffe.13402 . hal-03157246

\author{
HAL Id: hal-03157246 \\ https://hal.science/hal-03157246
}

Submitted on 3 Mar 2021

HAL is a multi-disciplinary open access archive for the deposit and dissemination of scientific research documents, whether they are published or not. The documents may come from teaching and research institutions in France or abroad, or from public or private research centers.
L'archive ouverte pluridisciplinaire HAL, est destinée au dépôt et à la diffusion de documents scientifiques de niveau recherche, publiés ou non, émanant des établissements d'enseignement et de recherche français ou étrangers, des laboratoires publics ou privés. 
This document is a personal copy of the accepted version of the paper:

Wang, Long, Nathalie Limodin, Ahmed El Bartali, et Eric Charkaluk. "Coupling of X-Ray Computed Tomography and Surface in Situ Analysis Combined with Digital Image Correlation Method to Study Low Cycle Fatigue Damage Micromechanisms in Lost Foam Casting A319 Alloy». Fatigue \& Fracture of Engineering Materials \& Structures 44, $n^{\circ} 4$ (2021): 916 -32. The final publication is available at https://doi.org/10.1111/ffe.13402.

\title{
Coupling of X-ray CT and surface in-situ analysis combined with DIC method to study low cycle fatigue damage micromechanisms in lost foam casting A319 alloy
}

\author{
Long Wang ${ }^{\mathrm{a}, 1}$, Nathalie Limodin ${ }^{\mathrm{a}}$, Ahmed El Bartali $^{\mathrm{a}}$, Eric Charkaluk ${ }^{\mathrm{a}, 2}$ \\ a Univ. Lille, CNRS, Centrale Lille, UMR 9013 - LaMcube - Laboratoire de Mécanique, Multiphysique, Multi-échelle, \\ F-59000 Lille, France
}

\begin{abstract}
An experimental protocol has been set up in order to study the Low Cycle Fatigue (LCF) damage micromechanisms in a Lost Foam Casting (LFC) A319 alloy at room temperature. The microstructure of the alloy was characterized by using X-ray Computed Tomography (X-ray CT) prior to the LCF tests performed with surface in-situ observations using a long distance microscope, which allow crack initiation and propagation being tracked in real-time. The mechanical fields measured by Digital Image Correlation (DIC) method allowed establishing the relations between strain localizations, damage evolutions and microstructure while a developed etching method, which gives a natural texture to the surface, makes DIC feasible to an acceptable resolution without masking the microstructure. The results showed that crack initiation is ascribed to strain localizations induced by large pore and/or the propagation of a previously nucleated crack. Cracks propagate along hard inclusions but the orientation of hard inclusions has also an influence on crack path.
\end{abstract}

Keywords: Al-Si alloys; Low cycle fatigue; Digital Image Correlation; In-situ observations; X-ray Computed Tomography; Damage micromechanisms

\footnotetext{
*Corresponding author: Long Wang (Email:long.wang.fr@hotmail.com; Tel. +86 1520138 8702)

${ }^{1}$ Present address: Science and Technology on Reliability and Environmental Engineering Laboratory, Beijing Institute of Structure and Environment Engineering, Beijing, China

2 Present address: LMS, CNRS, Ecole Polytechnique, Institut Polytechnique de Paris, Palaiseau, France
} 


\section{Introduction}

Thanks to its castability and mechanical properties, A319 alloy belonging to commercial cast AlSi alloys, is widely used in automotive components such as for cylinder head of engine where the alloy should undergo Low Cycle Fatigue (LCF) loading due to the engine startup and shutdown ${ }^{1-8}$. A319 alloy is a hypoeutectic Al-Si alloy with two main solidification stages: (1) formation of aluminum rich $(\alpha-\mathrm{Al})$ dendrites, (2) development of two-phase (Al)-Si eutectic ${ }^{3}$. However, the presence of additional alloying elements such as $\mathrm{Mg}$ and $\mathrm{Cu}$, as well as of impurities such as $\mathrm{Fe}$, leads to more complex solidification reactions and thus results in complex multiphase microstructures that have an influence on the macro mechanical properties ${ }^{3,8}$.

Since a decade, the traditional casting process in automotive industry, i.e. the Die Casting (DC) process, is being replaced by the Lost Foam Casting (LFC) process in order to optimize geometry, reduce cost and control consumption ${ }^{9,10}$. However, the A319 alloy casted by LFC has a much shorter LCF life than that by DC due to a slower cooling rate in LFC which results in numerous large pores and a coarser microstructure ${ }^{11}$. Understanding the microstructures in A319 alloy casted by LFC and especially their influence on the LCF damage mechanisms is crucial for the casting process improvement and the strength and life prediction.

Some studies ${ }^{12-19}$ have been performed to understand the damage mechanisms of A319 alloy in past years. Large pores above a critical size are assumed to be the most likely crack initiation sites ${ }^{12,17}$; while hard inclusions, i.e. eutectic Si, iron intermetallics and copper containing phases are generally responsible for crack propagation but also for crack initiation in the absence of large pores ${ }^{13-19}$. However, most of the studies were performed in High Cycle Fatigue (HCF) regime. Only a few studies focus on the damage mechanisms of Al-Si alloys with large casting defects in LCF regime ${ }^{11,20}$. Moreover, even if post-failure analysis allows identifying defect at initiation site, it does not allow establishing the relation between crack growth and microstructure. This analysis is made even more difficult in LCF as failure often results from multicracking rather than from a single crack ${ }^{18}$. Recently, 3D in-situ analysis with X-ray Computed Tomography (X-ray CT) has been used to study the damage mechanisms of A319 alloy in LCF by the authors ${ }^{21,22}$. It allows following crack initiation and propagation in the bulk of material and highlights the influence of the strain localizations due to the pores on crack initiation. However, the understanding of the damage mechanisms during the propagation stage is quite limited due to the non-real-time method as only a few scans could be recorded during the LCF tests and the damage evolutions during two scans could not be observed. 
In order to further study the LCF damage micromechanisms in LFC A319 alloy, an experimental protocol, that not only allows following crack initiation and propagation on surface in real-time but also measuring surface in-plane displacement and strain field and linking the surface damage evolutions with the defects below surface, has been set up. At first, the microstructure of the LFC A319 alloy was characterized by using X-ray CT and Scanning Electron Microscope (SEM) together with Energy Dispersive Spectroscopy (EDS). Laboratory Computed Tomography (Lab-CT) was used to characterize pores in the bulk of specimen for the selection of the region where the following in-situ observation will be performed, as well as for the comprehensive analysis after failure. LCF tests were performed with surface in-situ observations to follow crack initiation and propagation in real-time. Post-mortem analysis using Optical Microscope (OM) and SEM completed the in-situ surface analysis. Digital Image Correlation (DIC) method was used to measure the mechanical full-fields during LCF tests. An etching method, which gives a natural texture to the aluminium dendrites by revealing segregation of $\mathrm{Si}$, was developed to make DIC feasible to an acceptable resolution without adding a speckle pattern that will also mask the microstructure. The relation between microstructure, crack initiation and propagation, and strain field was established by using the developed experimental protocol and thus help to reveal the LCF damage mechanisms in LFC A319 alloy.

\section{Material and experimental methods}

\subsection{Material}

The material used in this study was extracted from an A319 (7.85 wt.\% Si, 0.30 wt.\% Fe, 3.05 wt.\% Cu, 0.19 wt.\% Mn, 0.28 wt.\% Mg) prototype cylinder head, which was manufactured using LFC process, from the most critical area, i.e. the fire $\operatorname{deck}^{22}$ (Fig. 1a).

2D characterizations were first performed using SEM together with EDS in order to identify the different phases. The microstructural constituents in the LFC A319 alloy are pores and hard inclusions including eutectic Si, iron intermetallics and copper containing phases (Fig. 2a). Iron intermetallics involve $\alpha$ and $\beta$ phases: $\alpha(\mathrm{AlFeMnSi})$ phase usually presents a "Chinese script" morphology (in Fig. $2 \mathrm{a}-\mathrm{b}$, the iron intermetallics marked by an arrow is an $\alpha$ phase), while $\beta$ (AlFeSi) phase almost always presents a needle-like morphology (Fig. 2c). The copper containing phases involve $\mathrm{Al}_{2} \mathrm{Cu}$ and $\mathrm{AlCuMgSi}$ phases the latter being always connected with the former (Fig. 2b-c). Both copper containing phases have a very complex microstructure while the size of AlCuMgSi phases is usually much smaller (less than $1 \mu \mathrm{m}$ ) than that of other hard inclusions. The copper containing phases may connect with the Al-Si eutectic phase (Fig. 2a) or with iron intermetallics ( $\alpha$ and $\beta$ ) (Fig. 2b-c). 
(a)

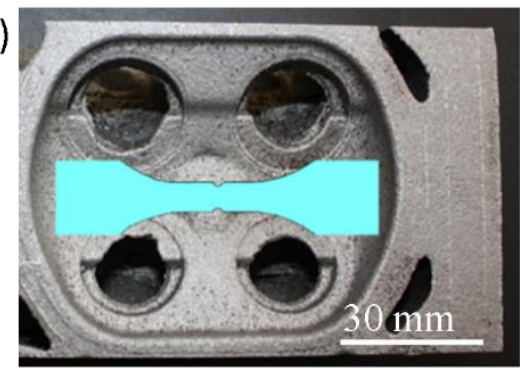

(b) $(\mathrm{mm})$

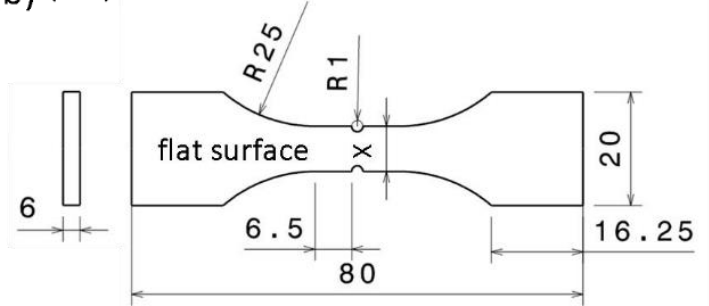

(c)
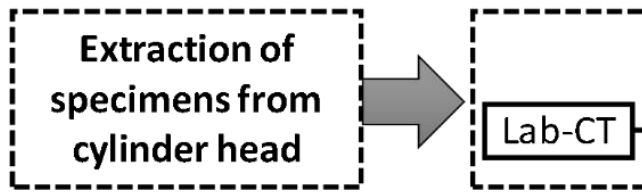

Selection \& Preparation

Figure 1: (a) Extractions of specimens from cylinder head; (b) size in mm of extracted specimen ( $X=10$ (resp. $=8)$, $($ Stress concentration factor $)=2.45$ (resp. = 2.3) for Specimen 1 (resp. Specimen 2)); (c) the procedure of extraction, preparation of specimens and selection of ROI.

(a)

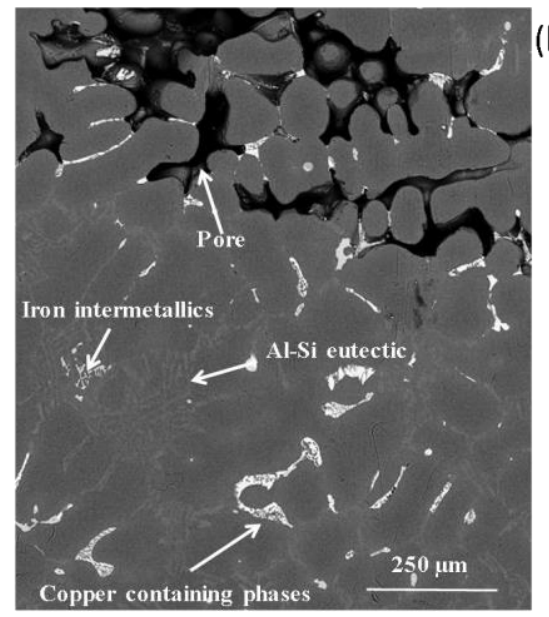

(b)

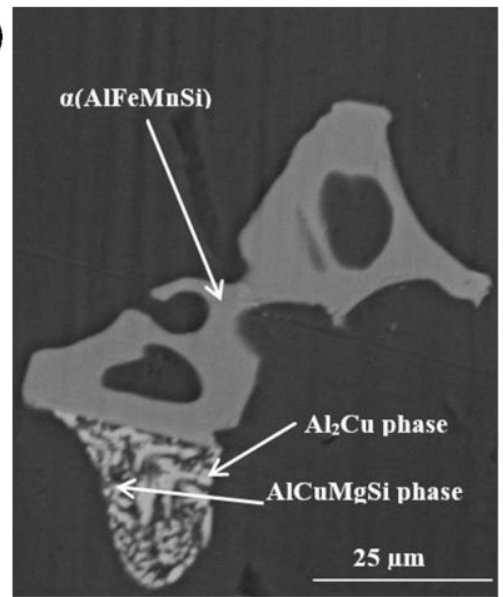

(c)

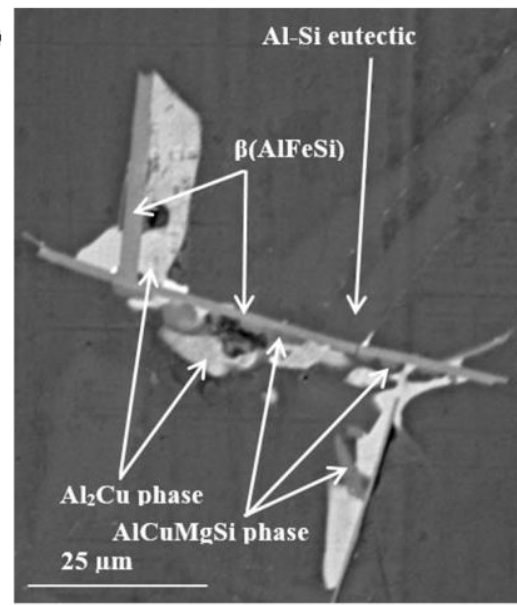

Figure 2: 2D characterizations of LFC A319 alloy using SEM (BSE images): (a) an overview of the microstructural constituents; $(b)$ and (c): higher resolution images reveal the details of iron intermetallics and copper containing phases.

3D characterizations were performed using X-ray CT in order to understand the complex microstructural morphologies of the constituents. The reader can refer to Ref. ${ }^{21}$ for the 3D characterizations of pores that have larger sizes than hard inclusions. This paper herein focuses on the $3 \mathrm{D}$ characterizations of hard inclusions while the reader can refer to Ref. ${ }^{3}$ for the experimental set-up details.

Fig. 3a (respectively $\mathrm{b}$ ) gives the 3D rendering of iron intermetallics (respectively copper containing phases) in the whole studied volume while Fig. 3c gives the $3 \mathrm{D}$ rendering of $\mathrm{Si}$ in a subvolume of $500 \times 500 \times 500 \mu \mathrm{m}^{3}$ to allow a better understanding of its morphology. Both Si and 
iron intermetallics (including $\alpha$ and $\beta$ phases that are connected in volume) form complex and highly interconnected networks and extend in the whole characterized volume, i.e. the maximum Feret diameter ${ }^{21}$ of individual segmented objects reaches the maximum size of the characterized volume; the example of iron intermetallics is shown in Fig. 3a. The copper containing phases, shown in Fig. 3b, are considered as a whole as $\mathrm{AlCuMgSi}$ phase cannot be distinguished from the connected $\mathrm{Al}_{2} \mathrm{Cu}$ phase due to its small size compared to the current resolution. They also form a complex microstructure but are less extended than $\mathrm{Si}$ and iron intermetallics with a maximum Feret diameter of $0.98 \mathrm{~mm}$ that is smaller than the maximum size of the characterized volume, i.e. $2.92 \mathrm{~mm}$. The volume fractions of the different microstructural constituents estimated under the current used resolution are: pores $\approx 1.0 \%{ }^{21}$, $\mathrm{Si} \approx 9.7 \%$, iron intermetallics $\approx 7.4 \%$, copper containing phases $\approx 1.3 \%{ }^{3}$.

(a)

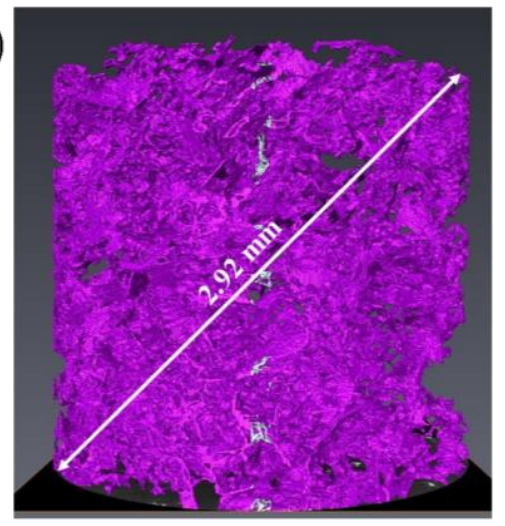

(b)

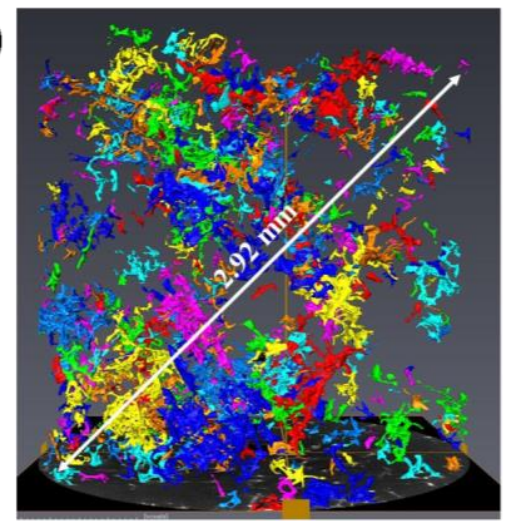

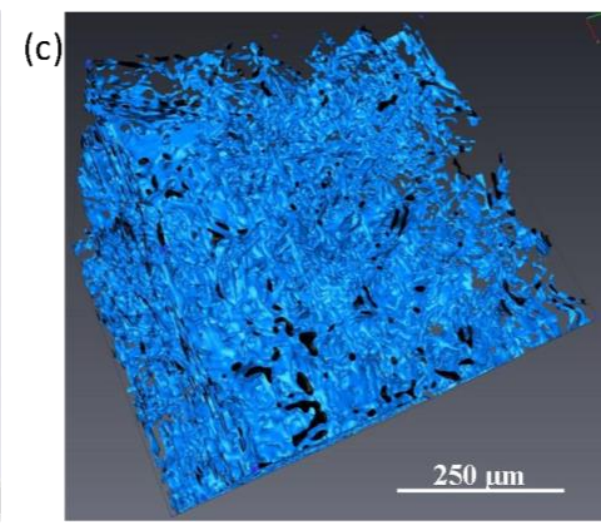

Figure 3: 3D rendering of (a) iron intermetallics, (b) copper containing phases and (c) Si in LFC A319 alloy.

The Feret diameter, which is used to characterize the size of pores, is no longer suitable to characterize the size of hard inclusions due to their interconnected and extended morphologies. Thus a granulometric analysis ${ }^{23}$, which measures the thickness distribution of a given phase, was introduced to characterize the size of hard inclusions. Fig. 4 compares the size distribution, i.e. Feret diameter for pores ${ }^{21}$ and local thickness for hard inclusions, of the microstructure constituents; the volumetric frequency is defined as the volume of phase having the considered size divided by the total volume of phase. Pores are much larger than hard inclusions. The pores having Feret diameter between $400 \mu \mathrm{m}$ and $1200 \mu \mathrm{m}$ represent $98 \%$ of the total volume of pores. In the same time, the iron intermetallics (respectively copper containing phases) having a local thickness between $6 \mu \mathrm{m}$ and $18 \mu \mathrm{m}$ represent more than $82 \%$ of the total volume of iron intermetallics (respectively copper containing phases) and the Si having a local thickness between $3 \mu \mathrm{m}$ and $12 \mu \mathrm{m}$ represent more than $99 \%$ of the total volume of Si. From a size point of view, the pores can be considered as the most critical defects in the volume. 


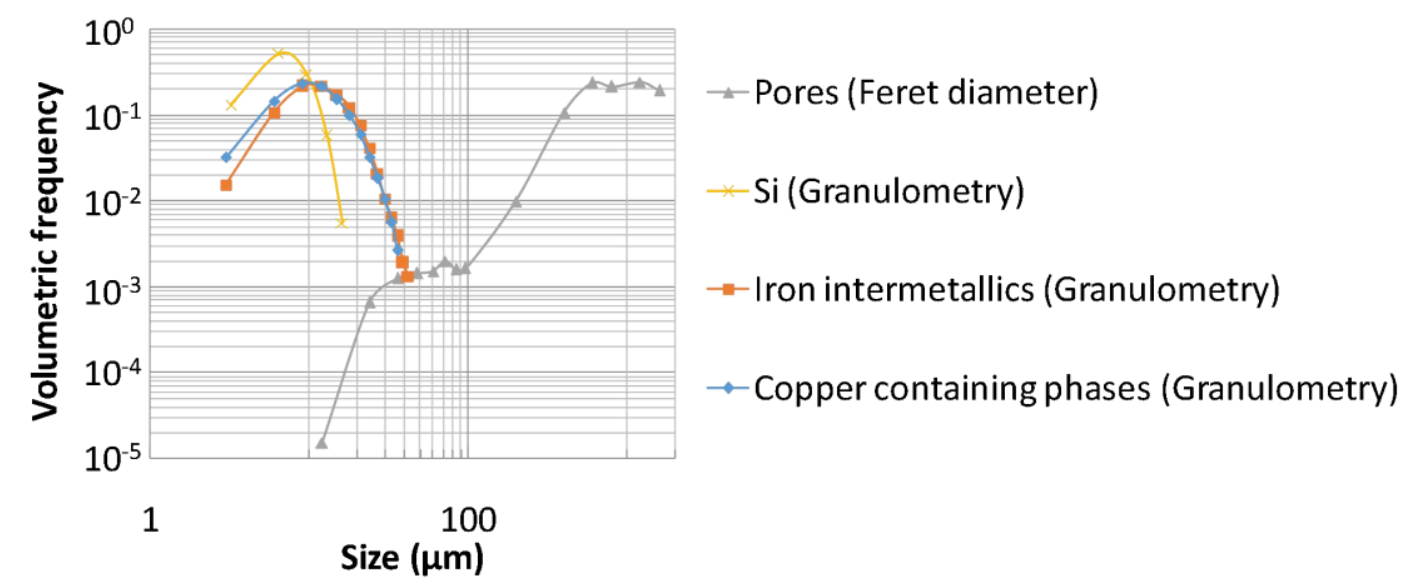

Figure 4: Distributions of pores, and hard inclusions, i.e. Si, iron intermetallics and copper containing phases, as a function of size (Feret diameter for pores, granulometry for hard inclusions).

\subsection{Specimens}

Two standard notched plate specimens (Fig. 1), named as "Specimen 1 and 2", were used for LCF tests with surface in-situ observations. Fig. 1c summarizes the procedure of extraction, preparation of specimens and selection of region of interest (ROI) where in-situ observations will be performed.

In order to ensure a high enough resolution for surface in-situ observations, the field of view is restricted. Thus, it is important to identify the area where cracks are most likely to initiate on surface in order to select this area as the ROI. Cracks are assumed to be more inclined to nucleate at large pores, especially at surface large pores ${ }^{12,14,17,24,25}$. Lab-CT allows pores in the bulk of specimen being revealed in 3D nondestructively ${ }^{21}$ and was thus used to select ROI: the selected areas have a cluster of subsurface pores or pores near the surface. Such a characterization of pores will also help to establish the relations between surface observations and pores in the bulk for comprehensive analysis after failure.

The key parameters of Lab-CT used for the characterizations of pores in the bulk of "Specimen 1 and 2" are listed in Table 1. The used resolutions (voxel size $\sim 6 \mu \mathrm{m}$ ) allow the large pores in the whole critical volume, i.e. notched area, to be revealed.

Grinding was performed on four sides and each corner of specimens using abrasive papers of grades up to 4000 grits in succession to ensure that all the surfaces are smooth and thus prevent the generation of stress concentration. A fine polishing was performed using polishing cloths and diamond suspensions up to $1 / 4 \mu \mathrm{m}$ for surface observations. The selected ROI was then recorded using OM to give an overview of microstructural constituents' morphology before loading. 
Table 1: Key parameters of Lab-CT used for the characterizations of pores in the bulk of "Specimen 1 and 2"

\begin{tabular}{|c|c|c|}
\hline Parameters & Specimen 1 & Specimen 2 \\
\hline Acceleration voltage & \multicolumn{2}{|c|}{$90 \mathrm{kV}$} \\
\hline Radiographies numbers & \multicolumn{2}{|c|}{1440} \\
\hline Scan duration & $6.35 \mu \mathrm{m}$ & $\sim$ One hour \\
\hline Voxel size & \multicolumn{2}{|c|}{$6.00 \mu \mathrm{m}$} \\
\hline
\end{tabular}

\subsection{Testing procedure}

The tensile-tensile fatigue tests were performed at room temperature with an Instron 8501 servohydraulic testing machine (Fig. 5a and b). The cyclic loading was controlled in displacement at a speed of $0.15 \mathrm{~mm} / \mathrm{s}$. During the test, the applied load was recorded and an extensometer, which was installed across the notched area of the specimen, was used to measure the macroscopic deformation (Fig. 5c). The Cartesian coordinate system is used to facilitate the understanding of the pictures (Fig.5 and the following figures) in this paper: ' $y$ ' is the loading direction, ' $z$ ' is the direction perpendicular to the specimen surface, while ' $x$ ' is the direction perpendicular to the ' $y z$ ' plane. Surface in-situ observations were performed at microstructural scale on surface, using Questar long distance microscope equipped with a JAi $500 \mathrm{CCD}$ camera. It allows the surface to be followed in real-time during tests. The surface on which optical observation was performed is called "flat surface" hereafter by opposition with the notch root called "notched surface". The Questar was mounted on a translation stage that allows displacement in three directions. The resolution, i.e. the pixel size, was adjusted with additional lens and by changing the distance between the specimen and the camera. The field of view, i.e. the diagonal length of one image of size $2456 \times 2050$ pixels $^{2}$, is about $1.2 \mathrm{~mm}$ with the used resolution, i.e. 1 pixel $\sim 0.38 \mu \mathrm{m}$. A coaxial lighting was used for surface observations, and its intensity was adjusted to give an appropriate texture, i.e. a good brightness without saturation and a high contrast resulting in a large gray value distribution for the digital images captured by CCD camera.

The tests were periodically interrupted with the specimen held under load when obvious damage evolutions were observed on surface, otherwise the tests were also interrupted after a few cycles (less than $10^{n+1} / 3$ cycles, i.e. at least 3 interruptions, for the tests performed between the $10^{n}$ th cycle and the $10^{n+1}$ th cycle, $n=0,1,2, \ldots$ ) even without evidence of damage evolutions (Fig. $5 \mathrm{a}$ ). Once the tests were interrupted, six images (3×2, named as 'Zone 0', 'Zone 1' ... 'Zone 5' in Fig. 5c) were taken in order 
to cover the selected ROI (about $2.7 \times 1.5 \mathrm{~mm}^{2}$ ). An appropriate overlap between adjacent images is necessary for the further stitching of the images to a larger one, which was performed using automatic Image Stitching plugins ${ }^{26}$ in ImageJ. The basic loading conditions of each specimen are listed in Table 2. Post mortem analyses were performed on the fracture surface by using OM and SEM in order to identify the possible crack initiation sites in fatigue and to study the fracture morphologies.
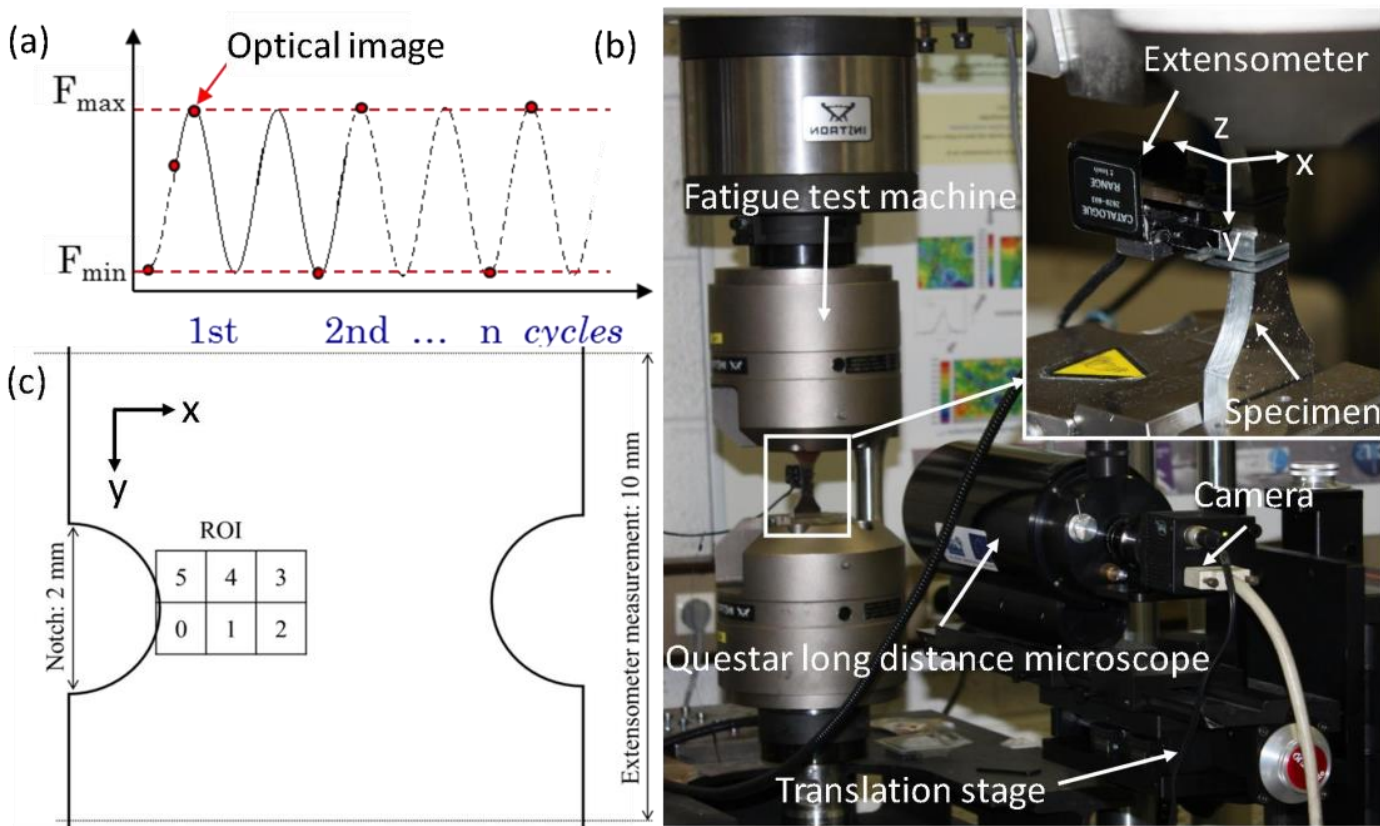

Figure 5: (a) Scheme of images acquisition during fatigue tests; (b) fatigue tests with surface in-situ observations; (c) Schema of DIC measurement and extensometer measurement.

Table 2: Basic loading conditions and results of tests

\begin{tabular}{|c|c|c|c|}
\hline \multicolumn{2}{|c|}{ Specimen } & $\mathbf{1}$ & $\mathbf{2}$ \\
\hline \multirow{4}{*}{ Loading conditions } & Max. stress (MPa) & 110 & $80 \sim 110$ \\
\cline { 2 - 4 } & R (Stress Ratio) & 0.2 & $0.1 \sim 0.2$ \\
\cline { 2 - 4 } & Average max. strain & $0.15 \%$ & $0.10 \%$ \\
\hline \multirow{4}{*}{ Results } & Crack initiation observed & After $7000 \mathrm{c.}$ & $1^{\text {st }}$ cycle (during initial tensile stage) \\
\cline { 2 - 4 } & Initiation site & Pore & Pore + Si (Possible) \\
\cline { 2 - 4 } & Propagation path & \multicolumn{2}{|c|}{ Hard inclusions (Si, iron intermetallics, copper containing phases) } \\
\cline { 2 - 4 } & Final failure (cycles) & $\approx 100000$ & 20430 \\
\hline
\end{tabular}




\subsection{Surface strain field measurement}

\subsubsection{Development of etching speckle pattern}

The surface full-field measurement was performed using DIC technique and the accuracy and the spatial resolution of the measurement directly depend on the presence of numerous and finely dispersed markers on the specimen surface ${ }^{27}$. This random texture is usually obtained through the application of a paint speckle pattern. The obvious drawback is that the speckle also masks the microstructure underneath and thus prevents the study of the relationship between microstructural features and strain heterogeneities.

Etching on polished surfaces may be an alternative to paint speckle as it can reveal the different phases hence increasing the image texture. Tint etching consists in the formation of a film whose thickness is different from one constituent to the other. Coloration is due to interference effects (under white light) in the deposited film so that a difference of film thickness will result in different colors. A change in etch duration will also result in a different film thickness and will thus give rise to a totally different set of colors. A Weck's reagent - $100 \mathrm{~mL}$ water, $4 \mathrm{~g} \mathrm{KMnO} 4$ and once dissolved $1 \mathrm{~g} \mathrm{NaOH}-$ was used for etching with a $14 \mathrm{~s}$ duration. This method reveals the segregation (coring) in the dendrites when applied to cast aluminum alloys ${ }^{28}$. Its main advantage is that it does not attack intermetallic phases and precipitates ${ }^{29}$ so that it is not expected to interfere with the damage mechanisms to be studied. Indeed, no pit or grooves were observed under SEM. The quality of the so obtained natural speckle can be assessed by comparing the gray-level distributions in the same area of the specimen surface before and after tint etching (Fig. 6a). Before etching, the histogram shows two narrow peaks, i.e. one small for the hard inclusions and one tall peak for the aluminum, as the image is almost binary. After etching, the image dynamic shows a wider range of gray-levels within the Aluminum matrix where etching has revealed Si segregation and a broad peak for hard inclusions within the interdendritic space. The large standard deviation of the gray-level distribution (Std. Dev. in Fig. 6a) of the specimen surface, as compared to that before etching, indicates a richer and more random speckle pattern whose suitability for image registration was tested. 
(a)

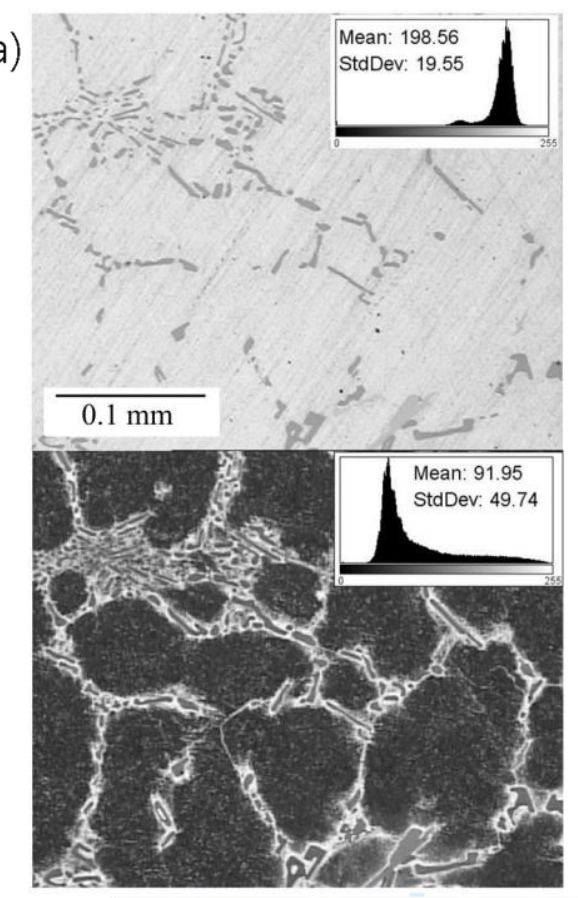

(b)

(c)

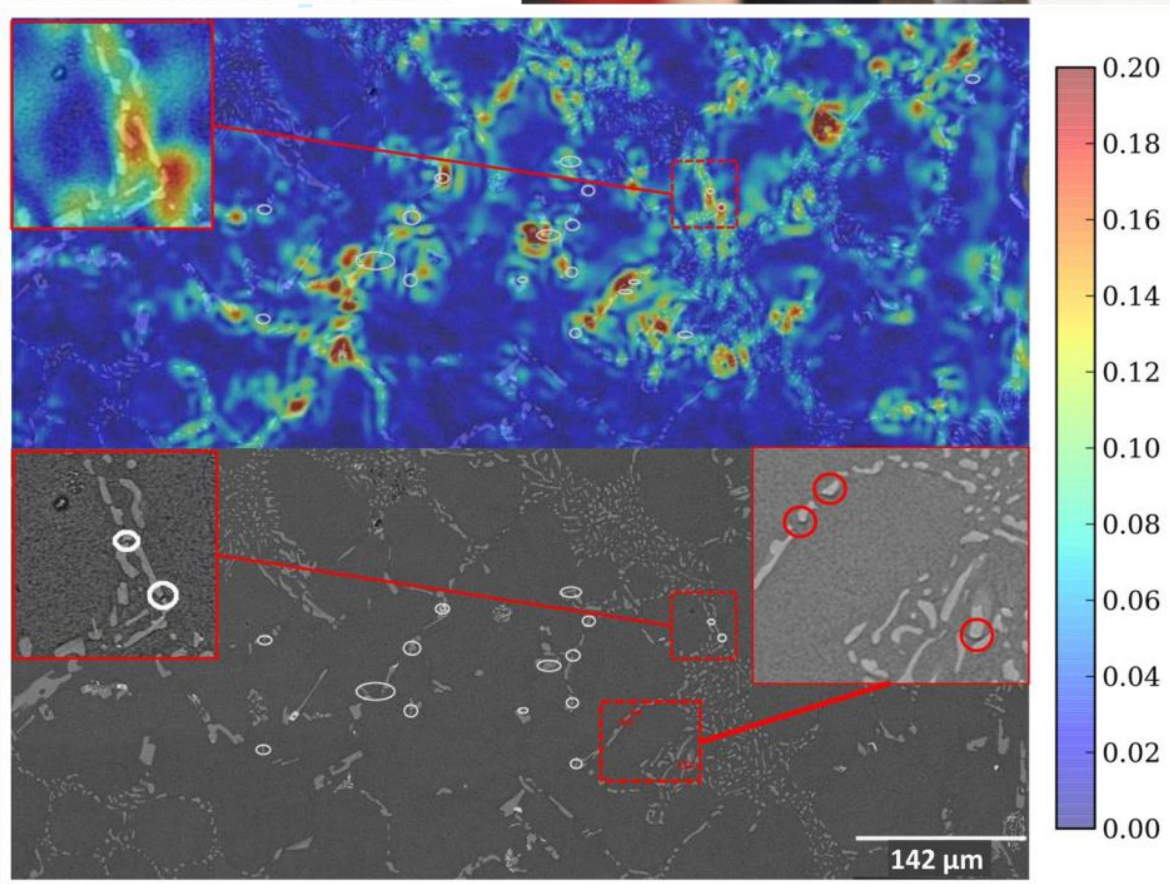

Figure 6: (a) Optical microscopy images of the specimen surface before (top) and after (down) etching; histograms show the dynamic of the corresponding image in 8bit format; (b) Experimental set-up with Questar microscope; the stress-strain curve of the test is compared to that of a conventional test; (c) Cumulated strain field computed from DIC at the last load step before failure $(237 \mathrm{MPa})$ and the corresponding SEM image showing fracture and debonding of Si particles; loading was along the vertical direction. 


\subsubsection{Validation of the developed DIC measurement method in tensile test}

In order to validate the ability of the developed DIC measurement method by using etching of the surface to reveal strain heterogeneity at the microstructure scale, this method was primarily applied in an in-situ tensile test performed on another Al-Si alloy (A356 alloy: 6.5-7.5 wt.\% Si, $<0.3$ wt.\% Fe, 0.25-0.4 wt. \% Mg). The natural tracers revealed using the etching method for A319 and A356 alloys are similar (Al matrix (majority) and hard inclusions) ${ }^{3}$. The tensile test was performed at a displacement rate of $1 \mu \mathrm{m} / \mathrm{s}$ using a servo-hydraulic testing machine (Fig. 6b). A small size dog-boneshaped specimen, i.e. minimum cross-section of the flat specimen is $1.43 \times 1.34 \mathrm{~mm}^{2}$, was used and a shallow notch was introduced to have a slight stress concentration in the central part of the specimen and force the damage events to occur in this area, i.e. ROI. The test was periodically interrupted with the specimen held under load and the in-situ surface observation system, i.e. Questar with camera, was used to capture images in four adjacent zones of the ROI with a pixel size in the image of about 0.338 $\mu \mathrm{m}$ in order to cover the whole specimen cross-section in the notch area. Stitching of the four adjacent images acquired at each load step was performed using the plugin Mosaic $\mathrm{J}^{30}$ in Image $\mathrm{J}$ software that allows rigid registration of images. DIC was performed using the publicly available computer program Elastix $^{31}$ for intensity-based image registration on the stitched images.

The measurement accuracy ${ }^{32,33}$ of DIC was evaluated through the comparison between a prescribed displacement and the displacement measured from DIC ${ }^{34}$. One reference image was taken on the specimen surface, then a given displacement (10 $\mu \mathrm{m}$ in the present case) was imposed on the Questar translation stage in a direction parallel to the specimen surface and the moving image was taken at this position. The uncertainty is estimated from the standard deviation of the displacement field measured by DIC between the two images, i.e. reference image and moving image ${ }^{35-37}$. The estimated uncertainty of DIC measurement in this study shows that the natural speckle pattern provided by color etching can be considered good enough to yield an uncertainty that remains low, i.e. $0.08 \mu \mathrm{m}$ (0.23 pixels), at a size of element small enough to result in a high spatial resolution, i.e. $10.72 \mu \mathrm{m}$ (32 pixels), in the measured field. Besides the average strain computed from the strain fields derived from the measured displacement fields allows to draw a stress-strain curve (represented with symbols in Fig. 6b) that is consistent with the curve obtained on larger specimens with appropriate extensometer 
measurement (represented with a plain line in Fig. 6b). Thus, the experimental protocol developed in this study to perform DIC at the scale of the microstructure can be used to understand damage mechanisms at a fine spatial scale in Al-Si cast alloys.

In Fig. 6c, strain heterogeneity is observed in the ROI of the specimen and was compared with SEM observations at a magnification large enough (500) to detect microcracks (circled in white in the lower image in Fig. 6c) that were not visible in the optical image. In fact, strain localization appeared in the eutectic Al-Si constituent at a stress level of $220 \mathrm{MPa}$ (average strain of about $0.44 \%$ ) and increased at a stress level of $237 \mathrm{MPa}$ (average strain of about $0.71 \%$ ). The comparison of the microcracks (white circles in Fig. 6c) and the debonding (red circles) of eutectic Si particles observed after the test with the strain field at the last loading step before failure shows (1) that most of the strain localization can be ascribed to Si particles and (2) that Si damage has occurred at areas where a strain localization was indeed visible at the last loading step of the tensile test. To the authors' knowledge, this type of comparison between DIC and fracture in such materials at such a scale is a new result.

Thus, the developed DIC measurement method established the relation between the strain heterogeneities and the damage events successfully in tensile tests. The monitoring conditions (camera, pixel size) are indeed similar to those of the fatigue test even if the size of the specimen and the loading conditions are different as larger specimens are preferred for fatigue test in order to study the propagation behavior. This method will then be used in the following fatigue tests.

\subsubsection{DIC measurement for fatigue test}

The polished specimens in 2.2 were etched by using the developed method in 2.4.1 on the selected ROI surface prior to the fatigue tests. The digital images acquired at the minimum loading of $1^{\text {st }}$ cycle was used as the reference for DIC measurements and the images acquired at the maximum loading of other cycles were used as moving images. A 32 pixels element size $(12.0 \mu \mathrm{m})$, which corresponds to an acceptable uncertainty $(0.09 \mu \mathrm{m})$, was selected.

\section{Results}

\subsection{Surface in-situ observation}

The basic results of the fatigue tests performed on Specimens 1 and 2 are listed in Table 2. Surface 
cracks were observed to initiate only in the selected ROI for both specimens. Thus, the selection of ROI using Lab-CT before fatigue tests was successful.

\subsubsection{Crack initiation}

In Specimen 1 (Fig. 7), no obvious cluster of pores was observed near the flat surface in the notched cross-section using Lab-CT. However, a surface pore located in the notch root (marked by arrows in Fig. 7a) is less than $0.1 \mathrm{~mm}$ from the flat surface. The pore's volume is about $0.012 \mathrm{~mm}^{3}$, and its max. Feret diameter is about $0.38 \mathrm{~mm}$. Fig. 7a and $\mathrm{f}$ show that the pore is rather spherical suggesting that it is a gas pore not a microshrinkage cavity. Although it is not very large compared with standard large pores in this material ${ }^{21}$, this pore is supposed to be the most probable crack initiation site on the observed surface through the comprehensive evaluation based on the influence of pores' size and location ${ }^{12,21,25}$ : (a) it is quite near the flat surface and the notch root contrary to other larger pores in bulk, (b) it is larger than other pores located on the observed surface. Thus, the flat surface area in front of this pore was selected as the ROI. In fact, Specimen 1 failed from a single crack (Fig. 7b) that nucleated at Si phase on the flat surface right in front of this pore. In order to check the influence of this pore on crack initiation, fracture analysis was performed.
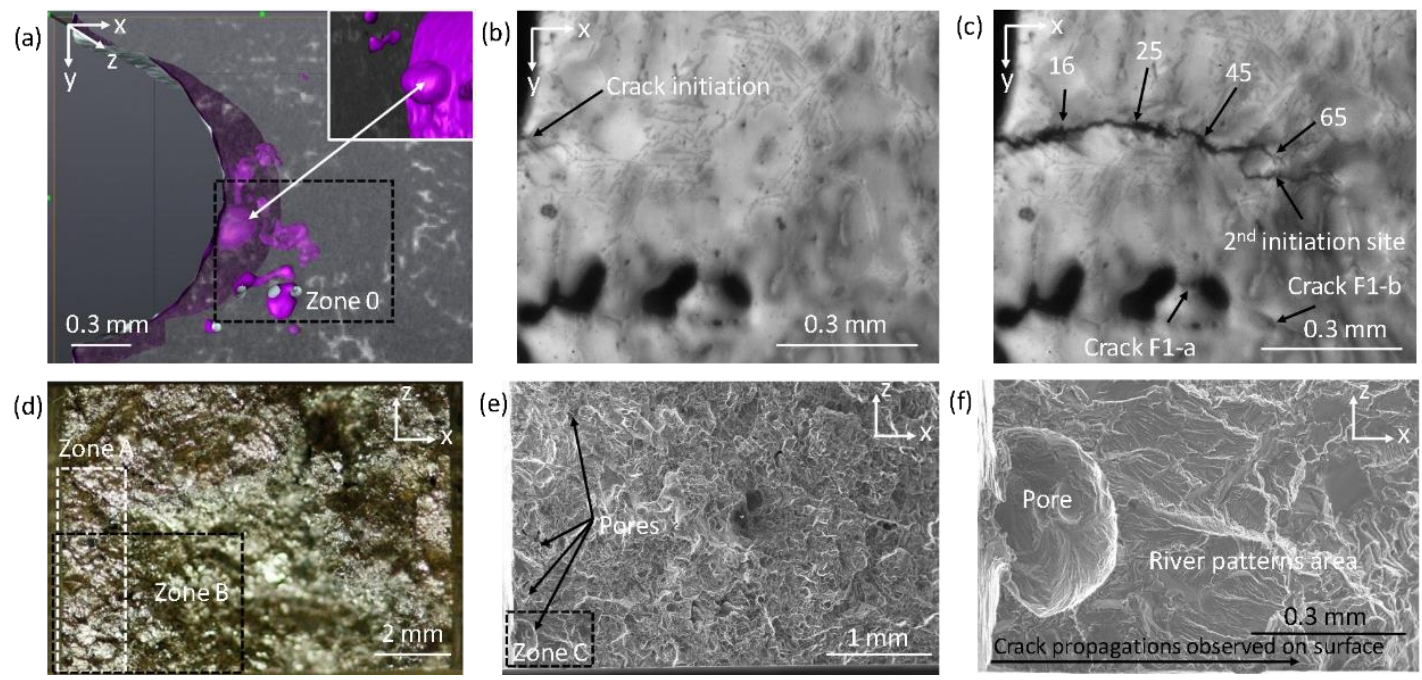

Figure 7: Specimen 1: (a) 3D rendering of pores near the selected ROI on flat surface while the surface is set transparent; in-situ observation images captured after (b) 7000 cycles and (c) 90000 cycles in Zone 0 of (a), the arrows with number indicate the position of the arrested crack tip after the number of loading cycles shown in units of 1000; (d) whole fracture surface; (e) SEM image of Zone B in (d); $(f)$ SE image of Zone C in (e).

One half of the broken specimen was observed using a single-lens reflex camera (Fig. 7d). Zone A is more likely to be crack initiation and propagation areas instead of final fracture area as it is more 
flat than other areas in fracture surface. River patterns ${ }^{38}$, of which the direction represents the direction of the crack propagation, were indeed observed around the above mentioned pore in Fig. $7 \mathrm{f}$ with a higher resolution. Thus, the crack initiation, which was observed on the flat surface, could be ascribed to this pore that is surface-breaking in the notch area but is some distance below the flat surface where in-situ observations were done.

SEM observations were also performed on the whole fracture surface. The area, i.e. Zone A in Fig. $7 \mathrm{~d}$, where the river patterns were observed corresponds to the area where crack initiated and propagated. The other areas without river patterns are the fast fracture area in the final stage of fatigue test. This is consistent with the in-situ surface observation as cracks were only observed to grow on surface above this area.

Several pores, marked by arrows in Fig. 7e, were found in the crack propagation area, i.e. Zone A. They present evidence of river patterns so that it is difficult to identify the first initiation site inside the specimen. There are several possible scenarios: (1) One crack initiated from one of these pores, and then grew through other pores towards the free surface. (2) Cracks initiated from several pores at the same time or at different cycles, and then coalesced during the propagation. (3) Cracks initiated from hard inclusions in bulk that are not connected with pores under the influence of the stress concentration induced by pores and then propagated through the pores.

By using surface in-situ observations and post-mortem analysis, one cannot confirm which case is the true scenario for the crack initiation and propagation in bulk. However, the influence of pores below the observed flat surface on crack initiation observed on surface is certain.

Fig. 8 presents a comprehensive analysis of Specimen 2 including 3D rendering of pores in the bulk of specimen (Fig. 8a), in-situ surface observations (Fig.8b, e), OM surface observation (Fig. 8d) and fracture analysis (Fig. 8c, f and g). In Specimen 2, cracks initiated on surface from five different sites identified as A, B, C, D, and E in Fig. 8b. Cracks initiated from sites A and B (Fig. 8e) before the maximum load of the $1^{\text {st }}$ cycle was reached, i.e. below an applied stress of 80MPa. The opening of these two cracks became larger with a further increase of the stress up to the maximum value of the $1^{\text {st }}$ cycle (in the top right of Fig. 8e). Thus, the maximum loading in the $1^{\text {st }}$ cycle was stopped at about 98 $\mathrm{MPa}$, which is lower than for Specimen 1. 
(a)

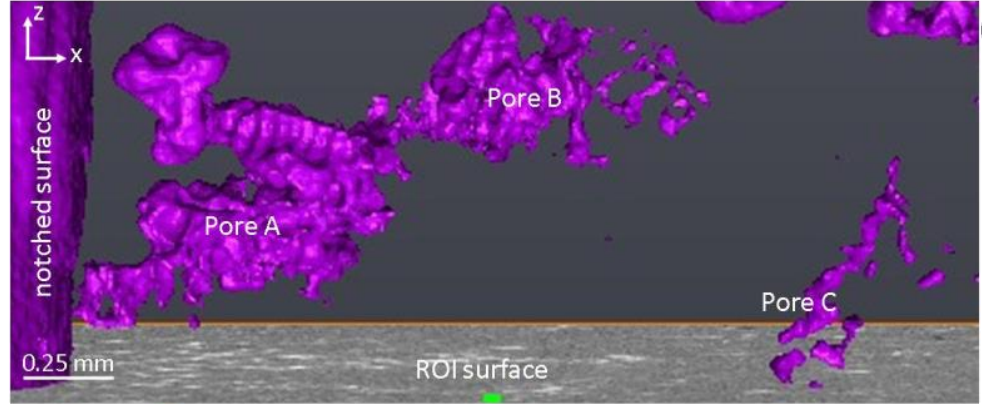

(b)

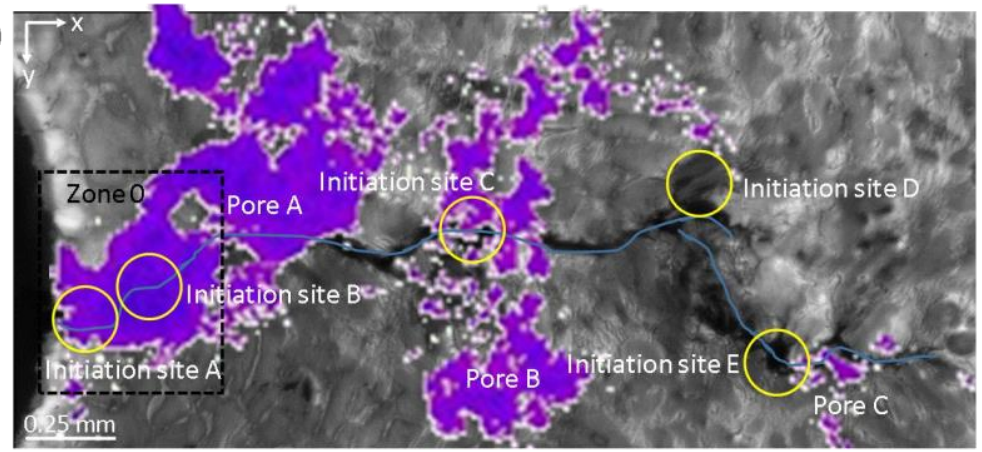

(c)

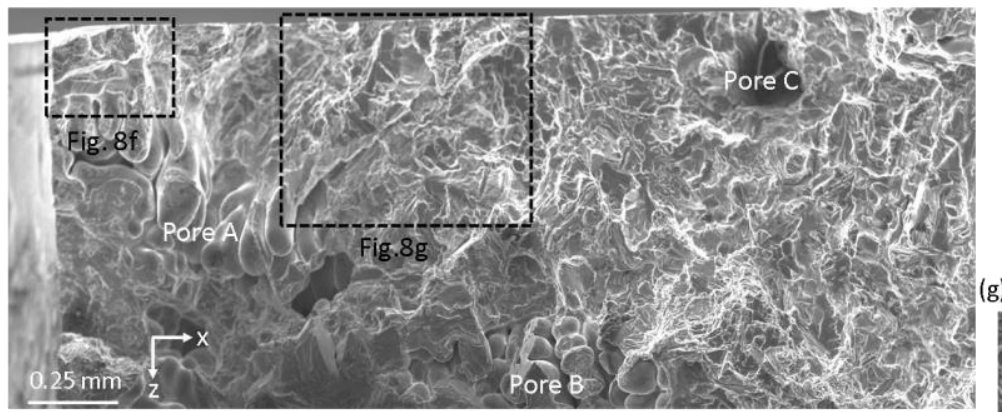

(d)
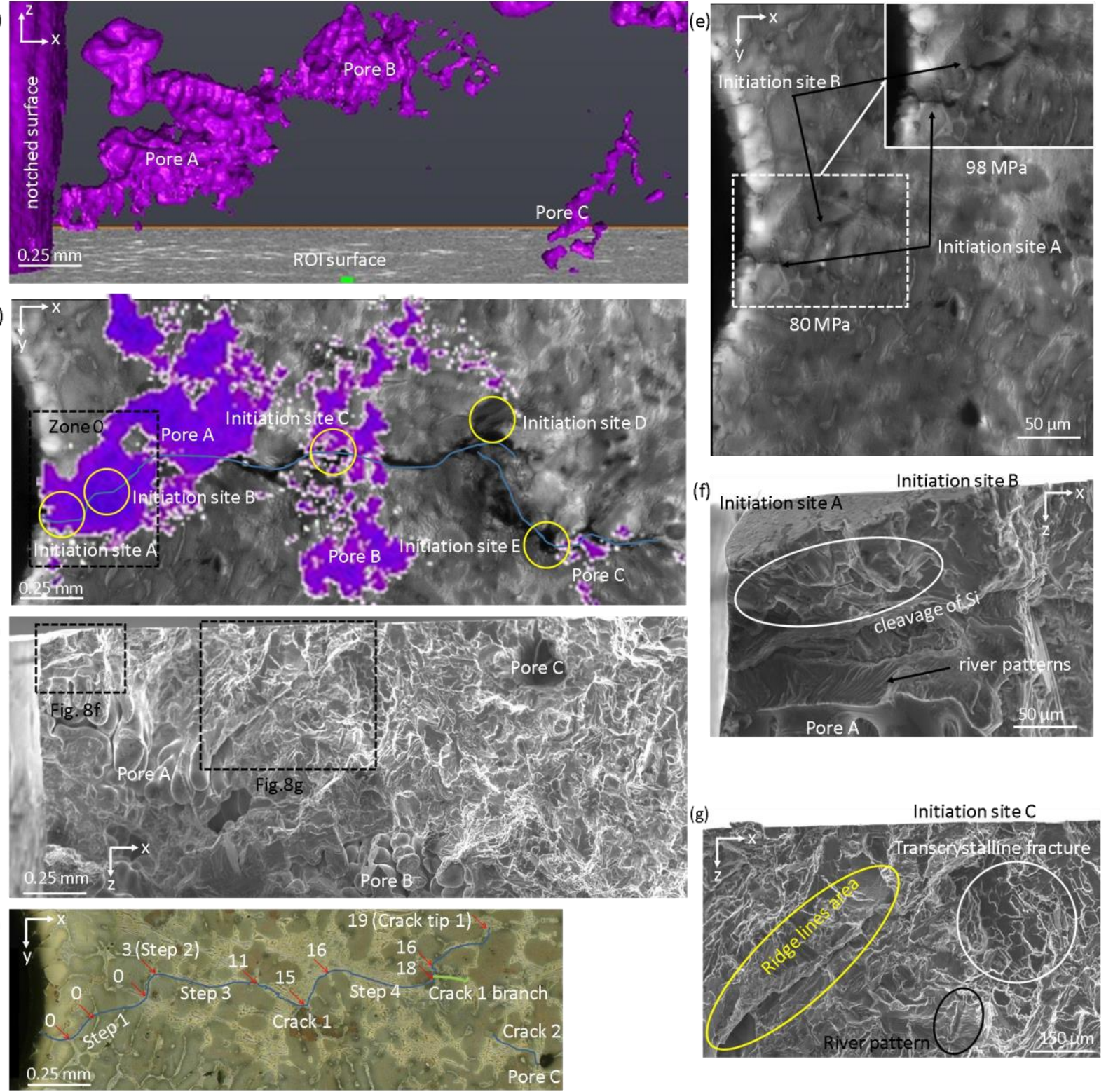

Figure 8: Specimen 2: (a) 3D rendering of a cluster of pores below the selected ROI on surface; (b) in-situ observation image (stitched using six images) captured after 20300 cycles with the 2D projection of 3D pores from (a) shown in purple and final fracture marked with blue line; (c) the fracture surface observed by SEM in the corresponding area shown in (b); (d) OM image in ROI with the observed crack marked with lines and the arrows indicate the position of the crack tip after the number of loading cycles shown in units of 1000; (e) in-situ observation images captured during tensile stage of 1st cycle (Zone 0 in $(b))$; $(f)(g)$ SEM image in the corresponding zones in (c).

SEM post-mortem analysis showed that these two crack initiation sites on surface were not only at hard inclusions but also in Al matrix and that they are located just above Pore A (Figs. 8a-c). Thus, the cracks were likely to have initiated from Pore A and then propagated to the flat surface. Fracture analysis in Fig. $8 \mathrm{f}$ shows that the distance between initiation sites A/B and Pore A is less than $0.1 \mathrm{~mm}$. 
The cracks initiated on surface at sites $\mathrm{A} / \mathrm{B}$ during the tensile stage of the $1^{\text {st }}$ cycle, thus the damage mechanisms could not be ascribed to fatigue but to the large stress concentration caused by the large Pore A in subsurface. This crack corresponds to brittle fracture zones with cleavage of Si (Fig. 8f).

Cracks were observed to initiate at sites C and D (Fig. 8b) suddenly between the $15860^{\text {th }}$ cycle and the $15890^{\text {th }}$ cycle. These two initiation sites were across hard inclusions and $\mathrm{Al}$ matrix and cracks opened very quickly. Pore B is below the initiation site C (Figs. 8a-c) at a depth of about $0.8 \mathrm{~mm}$ as shown in Table 3. Although the river patterns marked in Fig. $8 \mathrm{~g}$ revealed the direction of cracks originated from the cleavage of a Si particle in a local area, one cannot obtain more information about crack propagation in a larger area. However, the 'ridge' line (Fig. 8g), which formed during the coalescence of cracks from two different planes $^{39}$, was observed between initiation site $\mathrm{C}$ and Pore A (Fig. 8c). This implies that crack initiation $\mathrm{C}$ may be due to coalescence of two cracks.

Table 3: Size and location of Pore A, B and C shown in Fig. 8

\begin{tabular}{|c|c|c|c|c|}
\hline \multirow{2}{*}{ Pore } & \multirow{2}{*}{ Feret diam. (mm) } & \multirow{2}{*}{$\begin{array}{c}\text { Connection with the } \\
\text { surface }\end{array}$} & \multicolumn{2}{|c|}{ Minimum distance to surface (mm) } \\
\cline { 3 - 5 } & 1.31 & Subsurface pore & 0.18 & Notched surface \\
\hline A & 1.37 & Subsurface pore & 0.80 & 0.02 \\
\hline B & 0.90 & Surface pore & 0.00 & 0.90 \\
\hline C & & & \multicolumn{2}{|c|}{} \\
\hline
\end{tabular}

Cracks were observed in-situ to initiate simultaneously at site $\mathrm{C}$ and at site $\mathrm{D}$ where post-mortem analysis confirms the presence of Si phase. Site D is not present on fracture surface as it is covered by the fracture surface caused by Crack 1 branch in Fig. 8d. No subsurface pore was found around initiation site D and no crack was observed to propagate to this area from other pores. Thus, hard inclusions may have acted as initiation sites at or around site D as hard inclusions are indeed observed to act as crack initiation site due to strain localizations in previous study by using $3 \mathrm{D}$ in-situ analysis $^{21,22}$.

Crack 2, which is marked in Fig. 8d, was observed to initiate from site E (Fig 8b) near Pore C after 19350 cycles. The influence of surface Pore $\mathrm{C}$ on crack initiation at site $\mathrm{E}$ is obvious.

\subsubsection{Crack propagation}

The cumulative crack lengths of Specimens 1 and 2 were measured using ImageJ software on insitu captured images for the quantitative analysis of crack propagation (Fig. 9a). The measured crack 
length corresponds to the distance between the initiation site at the notch root and the farthest crack tip. Crack observed on surface of Specimen 2 is much longer than that of Specimen 1 due to numerous large near surface pores in Specimen 2 (Figs. 7-8).
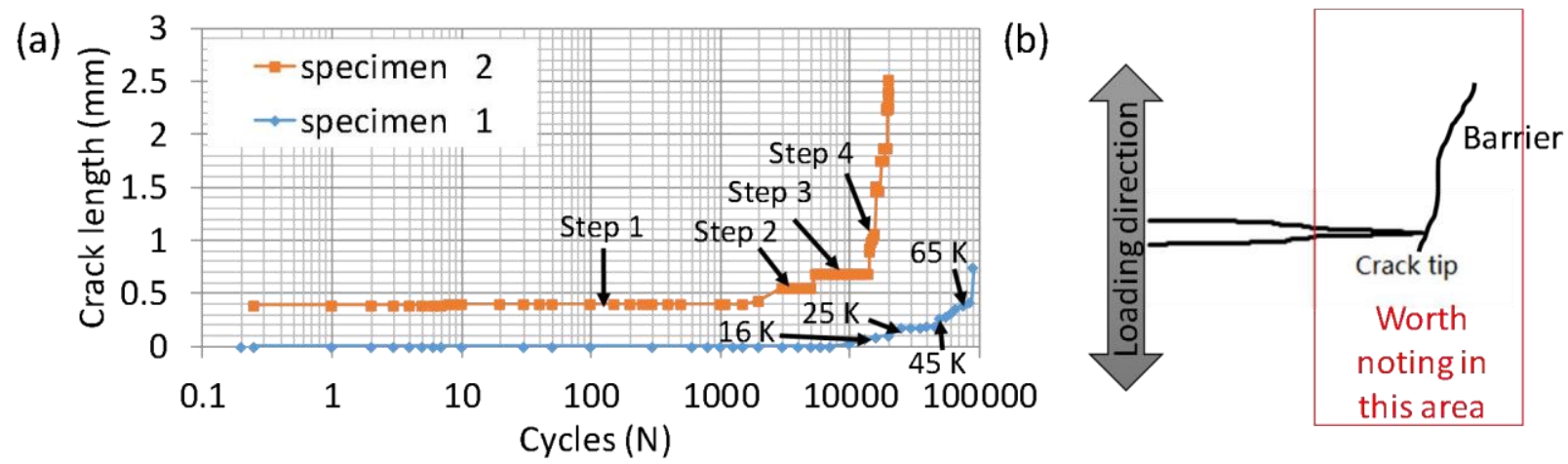

Figure 9: (a) Crack length evolution with number of cycles; (b) schematic drawing of the area where crack tip is arrested by barrier.

In Specimen 1, crack initiating at Si particle after 7000 cycles (Fig. 7b) propagated along hard inclusions, including Si phase, iron intermetallics (both $\alpha$ and $\beta$ phases), $\mathrm{Al}_{2} \mathrm{Cu}$ and $\mathrm{AlCuMgSi}$ phases, until 65 000cycles where the crack tip was arrested by hard inclusions (Fig. 7c). Meanwhile, another crack initiated at hard inclusions at a $2^{\text {nd }}$ initiation site below the arrested crack tip (Fig. 7c) after 85000 cycles. Inside the specimen, this secondary crack may be a branch of the main crack as it is close to the arrested principal crack tip (Fig. 7c) or it may also be an independent nucleation site. However, one cannot confirm it using fracture analysis as the $2^{\text {nd }}$ initiation site is covered in the final fracture surface. The principal crack was arrested until final failure. When the crack from the $2^{\text {nd }}$ initiation site (Fig. 7c) connected with this principal crack after 90000 cycles, failure occurred quickly.

After nucleation at sites A and B in Specimen 2 at $1^{\text {st }}$ cycle, cracks were arrested for more than 2000 cycles (step 1 in Figs. 8d and 9a) by hard inclusions perpendicular to each crack tips. Once the hard inclusions had failed, the two cracks grew again and connected on surface. Both cracks (Fig. 8e) coalesced due to crack propagation below the surface under cyclic loadings as river patterns were observed between Pore A and these two initiation sites (Fig. 8f). Then, this coalesced crack was observed to propagate along hard inclusions (step 2 and 3 in Figs. 8d and 9a). After 15860 cycles, one crack, which has nucleated from Pore A, propagated towards site $\mathrm{C}$ on surface, and another crack initiated at site D on surface. They joined with each other (step 4 in Figs. 8d and 9a) and also joined with the cracks that nucleated from site A/B through cracks growth along hard inclusions after 18000 cycles. Transcrystalline fracture ${ }^{40}$ was observed in the fracture surface below site D (Fig. $8 \mathrm{~g}$ ). It may 
be caused by monotonic loading when cracks coalesced between sites $\mathrm{C}$ and D. However, one cannot confirm it just from fracture analysis. This large coalesced crack, i.e. Crack 1 in Fig. 8d, propagated until Crack tip 1 where the crack was arrested by hard inclusions. Then, Crack 2 propagated along hard inclusions towards the arrested Crack 1 (Fig. 8d). In the same time, a branch crack propagated in the direction perpendicular to the loading direction and along hard inclusions. When Crack 2 coalesced with the branch of crack 1 after 20400 cycles, fracture occurred in the following 30 cycles.

\subsection{DIC measurements}

DIC measurements are then applied to measure the surface in-plane displacement and strain field for the comparisons with the observations shown in section 3.1.

For Specimen 1, the cracks initiated in Zone 0 after 7000 cycles and the propagation remained in Zone 0 (Fig. 7c) even in the last in-situ observation step (about $10^{5}$ cycles) before final failure; no cracks could be observed in the other five zones. On the contrary for Specimen 2, the cracks initiated in Zones 0 and 5 during the tensile stage of $1^{\text {st }}$ cycle and they were in-situ observed to grow in all the six zones before final failure.

DIC measurements were performed between the reference image at the minimum load of the $1^{\text {st }}$ cycle and the images at the maximum load of different cycles. The average longitudinal strain deduced from DIC at the maximum loading of different cycles in Zones 0 and 2 of Specimen 1 and that in the whole ROI of Specimen 2 are shown in Fig. 10. The macroscopic average strain measured by extensometer is also shown for comparison.

For both Specimens 1 and 2, the average longitudinal strain, deduced from DIC, in notched area zones was a little larger than the macroscopic average strain measured by the extensometer due to the strain localization in this area. This localization is more significant around the notch root; indeed, the average strain measured by DIC in Zone 0 is generally higher than that in Zone 2.

It should be mentioned that the measured strain localizations in the field from DIC may arise by the possible out-of-plane displacement that induce errors for DIC measurements as 2D-DIC method (instead of 3D-DIC method) is applied in the present study. In addition, the following two situations should also be considered: (1) Before crack initiation, they represent the real localizations in the case of the nonexistence of out-of-plane displacement; (2) After crack initiation, they indicate the discontinuities appeared at the crack. For Specimen 1, DIC measurements are focused on two zones: Zone 0 where crack initiation and propagation were observed and Zone 2 where no crack was observed. 
Cracks were observed to initiate in Zone 0 due to the pores below the surface in an area where a larger deformation was indeed measured. During the fatigue test, the gap (Fig. 10) between the measured strain in Zone 0 and that in Zone 2 grew larger after crack initiation in Zone 0 after 7000 cycles: the measured strain in Zone 2 is basically below $0.2 \%$ while that in Zone 0 increases from less than $0.3 \%$ to more than $0.5 \%$. Thus, as mentioned above, the large deformations measured by DIC for Zone 0 of Specimen 1 from 7000 cycles in Fig. 10 were mainly induced by the discontinuities appeared at the crack. The similar situation was also observed for Specimen 2. On the contrary, the average strain in Zone 2 of Specimen 1, where there is no crack, keeps relatively constant during the test.

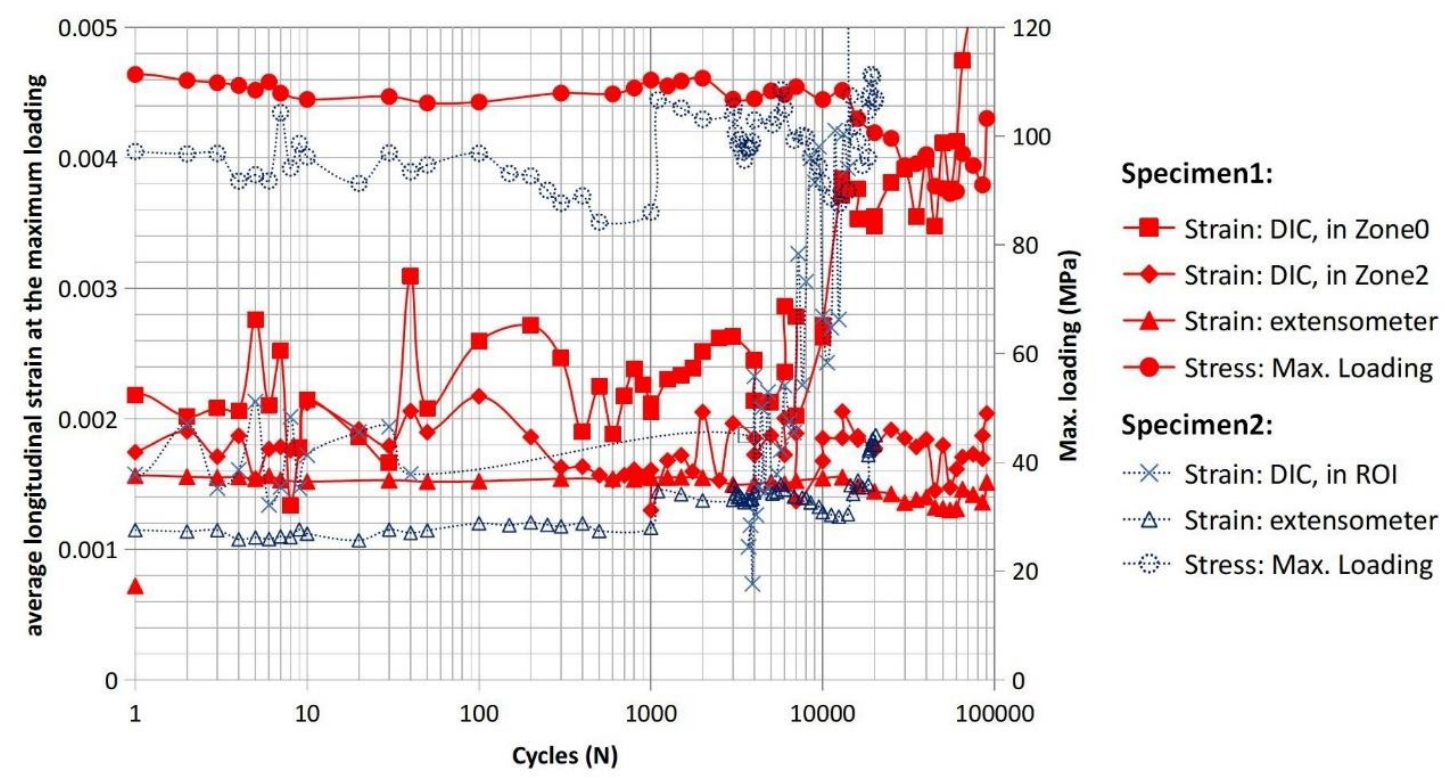

Figure 10: Evolution of average longitudinal strain in Specimens 1 and 2, as measured by extensometer and DIC at the maximum load, with the number of cycles.

Several examples of strain fields measured by DIC for both Specimens 1 and 2 are shown in Figs. 11 and 12. The deformed image, i.e. the image taken at the corresponding cycle, was put behind the measured field to allow its comparison with surface microstructure. In fact, as the measured fields are related to the reference image instead of the deformed images, a little difference may exist between the translucent field and the microstructure behind.

In Fig. 11, the large deformations at the cracks (see red areas in Fig. 11) are caused by opening of cracks. In the areas marked with circles in (a) and (b), strain localizations ( $>3 \%$ for (a), while $>6 \%$ for (b)) occurred while there was still no crack. Surface crack passed through the area marked in (a) in the following cycles, and a $2^{\text {nd }}$ crack initiated in the area marked in (b). Thus, strain localizations were measured in these areas prior to the observations of cracks on surface. Besides, the strain measured by 
DIC in the areas marked with circles in (a) and (b) may also be overestimated as out-of-plane deformation may have occurred in these areas where cracks appeared in the following cycles.

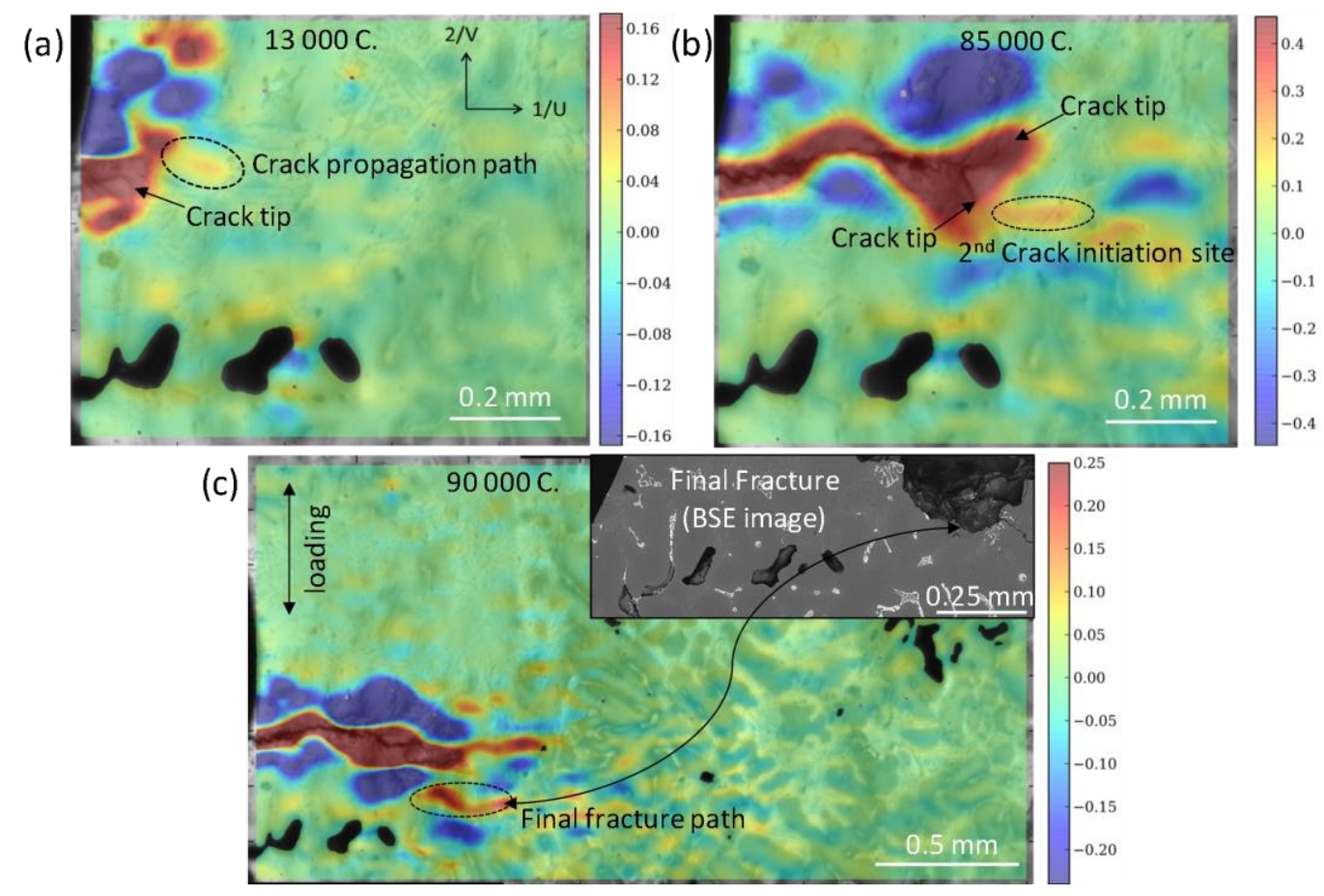

Figure 11: DIC strain (E22) measurement of Specimen 1: (a) 13000 cycles and (b) 85000 cycles in zone 0; (c) 90000 cycles (last step before final failure) in the ROI shown with BSE image of final fracture in the top right.

One example of strain fields in the whole ROI of Specimen 1 is shown in Fig. 11c. Besides the Zone 0 (the lower left corner area in the stitched image), no obvious strain localization was observed until the last step before failure (after 90000 cycles). The DIC performed in the other five zones highlights the role of strain localizations in crack nucleation from another perspective: no strain localizations no crack nucleation. Besides, the strain localization (marked by a circle in Fig. 11c) prior to the appearance of crack occurred where the final fracture took place.

The relations between strain localization and crack were also observed for Specimen 2 in Fig. 12. The crack tips after 18410 cycles are marked by arrows, and the cracks initiated from sites C and D have not connected yet. The strain localizations measured in the area (marked with a white circle around Initiation site E) where a secondary crack initiated around the surface pore after 19350 cycles when the main crack was arrested by hard inclusions around crack tip, indicates the influence of strain localizations on crack initiation. Meanwhile, the strain localizations measured in the area (marked with a white circle between crack tips) where two separate cracks connected on surface in the following cycles are mainly ascribed to the coupling influence of the two separate crack tips. 


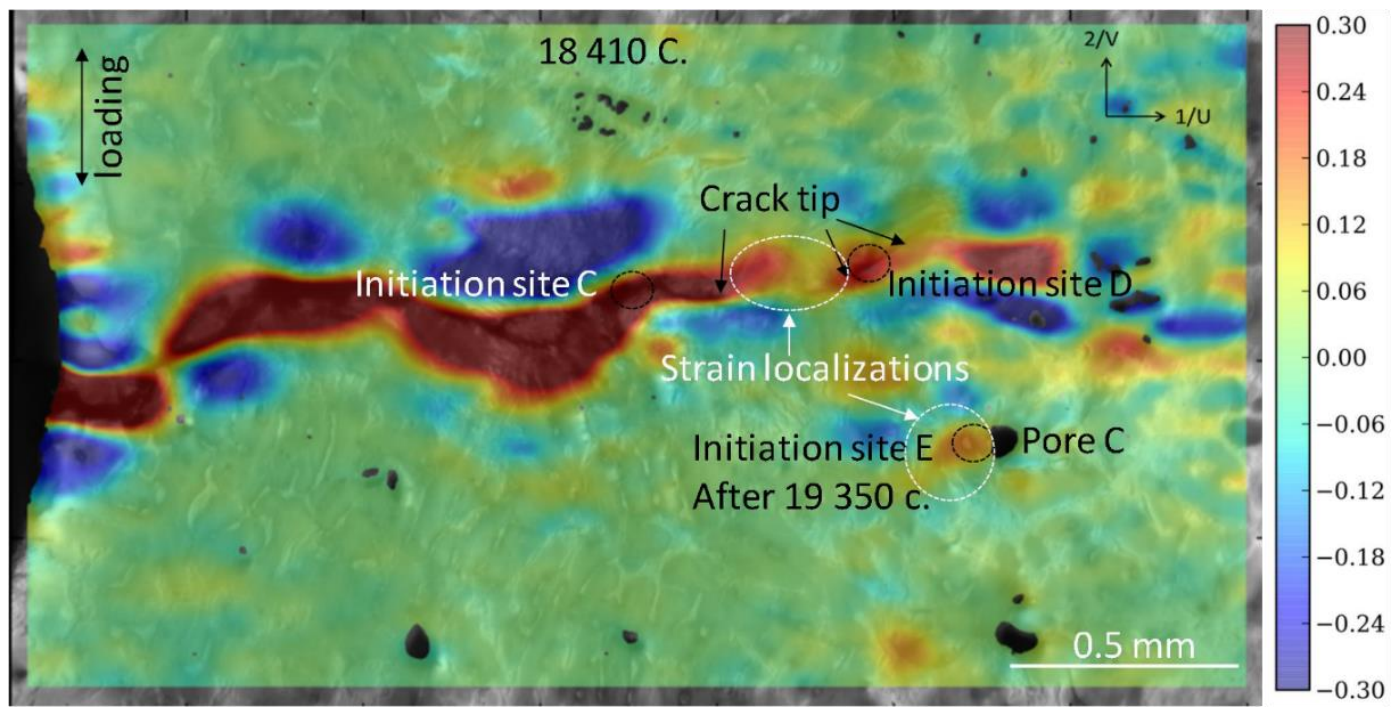

Figure 12: DIC strain (E22) measurement Specimen 2: 18410 cycles in the ROI.

\section{Discussion}

\subsection{Crack initiation}

Pores are assumed to be the most probable crack initiation sites in $\mathrm{HCF}^{12,14,17,24,25}$ and in LCF as demonstrated in a previous study in the laboratory ${ }^{21,22}$. They were thus characterized in the bulk of specimens using Lab-CT to identify possible crack initiation areas, i.e. ROI. The successful selection of ROIs for both tested specimens confirms the role of pores for crack initiation. Even if the pores are below the flat surfaces for surface in-situ observations, their influence on crack initiation on surface are further confirmed through the comprehensive analysis using surface in-situ observations, fracture analysis by SEM and OM and 3D characterizations of pores by Lab-CT (Figs. 7 and 8).

Thus, pore is undoubtedly the most important microstructural feature for crack initiation in the present A319 alloy under LCF loading. This is firstly ascribed to the large pores formed in this alloy due to LFC process ${ }^{21}$ : the minimum size of pores around which cracks initiated on surface in the tested specimens is $0.4 \mathrm{~mm}$, which is much larger than the critical sizes in the literature ${ }^{12,17}$.

The location of pore is also demonstrated to be an important factor on crack initiation: Cracks initiated around a surface pore at the notch root in Specimen 1 (Fig. 7) instead of other larger pores far from surface; In Specimen 2 (Fig. 8), more cracks initiated from the near surface Pore A and the surface Pore $\mathrm{C}$ than from the larger subsurface Pore B (Table 3).

The comparison between the two tested specimens implies that the number of large pores has an influence on crack initiation and fatigue life. In Specimen 2, which has more large pores near surface 
than Specimen 1, cracks initiated on surface in the tensile stage of $1^{\text {st }}$ cycle while cracks initiated on surface of Specimen 1 after 7000 cycles. Specimen 1 has a longer fatigue life than Specimen 2 while the former has a higher loading. Thus a large number of surface or near surface large pores accelerates crack initiation and also reduces fatigue life ${ }^{41}$.

A previous study in the laboratory ${ }^{21,22}$ shows that the strain localizations around large pores are responsible for crack initiation. In addition to large pores, hard inclusions may have also acted as individual crack initiation site, such as $2^{\text {nd }}$ crack initiation site for Specimen 1 (Fig. 7c) and Initiation site D for Specimen 2 (Fig. 8b). However, these initiation sites are not the initial nucleation sites. Cracks nucleated at these sites with the propagation of main crack on surface. The most likely reason is that the local strain levels in these sites are increased by the propagation of main crack and thus result in failure of hard inclusions. DIC measurements indeed show the strain localizations at these sites. For example, strain localization is observed at $2^{\text {nd }}$ Crack initiation site before crack nucleation in Fig. 7b. Thus, crack initiation can be ascribed to strain localizations induced by: (1) large pore; (2) the propagation of a formerly nucleated crack; (3) their coupling influence. Fig. 12 demonstrates the third case: with the coupling influence of the propagated main crack and the large Pore $\mathrm{C}$, strain localizations are observed at Initiation site E at $18410 \mathrm{c}$. before crack nucleation after 19 350c.

\subsection{Crack propagation}

Once cracks nucleated on surface, they were observed to propagate along hard inclusions under cyclic loading. The influence of the direction of hard inclusions on crack propagation was observed for both specimens. When the direction of the crack propagation was along the direction of the longest axis of hard inclusions at the surface, the crack grew quickly. However, when the direction of crack propagation was perpendicular to the direction of hard inclusions, the crack may be arrested ${ }^{42}$. For Specimen 1, cracks arrest at hard inclusions was observed at 16/25/45/65 K cycles marked in Fig. 7c; the corresponding points were also marked in the crack propagation curve in Fig. 9a. More crack arrests were observed for Specimen 2 as shown in Fig. 8d. The crack grew slowly when its tip encountered hard inclusions having their long axis perpendicular to the crack propagation direction. The crack tip needed many cycles to pass these barriers by two ways (Fig. 7c and Fig. 8d): (a) Change its propagation direction, i.e. grow along these barriers. Once these barriers have been bypassed, the crack propagated along a new route perpendicular to the loading direction. (b) Break these barriers. Once the arrested crack has passed these barriers, it grew very fast.

When cracks were arrested by the barriers, some similar phenomena were observed in the area 
(Fig. 9b) around the crack tip and along the loading direction:

- For Specimen 1: (a) When crack tip was arrested at $45 \mathrm{~K}$ cycles in Fig. 7c, Crack F1-a, which is just below the arrested crack tip, initiated at Si particle between two surface pores, which are actually one pore that is connected in subsurface as shown in the Lab-CT observation (Fig. 7a). (b) When crack tip was arrested at $65 \mathrm{~K}$ cycles, Crack F1-b, which is just below the arrested crack tip, initiated at copper containing phases. In the same time, crack initiated at hard inclusions (iron intermetallics, $\mathrm{Al}_{2} \mathrm{Cu}$ phase and $\mathrm{AlCuMgSi}$ phase) at $2^{\text {nd }}$ initiation site, which is also below the arrested crack tip.

- For Specimen 2: When the main crack was arrested by hard inclusions at crack tip 1 (Fig. 8d), Crack 2 initiated on surface around Pore C after 19350 cycles. Although strain localizations are easily generated around such large pores, no crack was observed before the crack was arrested at crack tip 1.

The above four secondary cracks, i.e. Crack F1-a, Crack F1-b, $2^{\text {nd }}$ initiation site for Specimen 1 and Crack 2 for Specimen 2, have a common feature: when the principal crack was arrested, they initiated from hard inclusions that are located in the same vertical direction as the main crack tip (Fig. $9 b$ ), i.e. the line through the principal crack tip and along a direction perpendicular to the crack propagation.

The failure of hard inclusions needs enough applied stress ${ }^{43}$. Thus, the above observations imply that stress concentrations may occur in the same vertical direction as the crack tip, i.e. the area marked in Fig. 9b, when the crack was arrested. Actually, such strain localizations are confirmed by DIC measurements, for example, $2^{\text {nd }}$ Crack initiation site for Specimen 1 in Fig. $11 \mathrm{~b}$ and Crack 2 for Specimen 2 (Initiation site E) in Fig. 12. As discussed in 4.1, it should be noted that initiation site $\mathrm{E}$ is a little away from the vertical direction of the arrested crack tip due to the combined effect of the stress concentrations caused by arrested crack tip and Pore C.

\section{Conclusions}

In order to study the LCF damage micromechanisms in LFC A319 alloy, an experimental protocol has been set up to establish the relations between microstructure, crack initiation and propagation and strain fields. The material was characterized thoroughly by using X-ray CT and SEM and Lab-CT was used to characterize pores in the bulk for the selection of ROI and to link the relations between surface observations and subsurface pores. LCF tests were performed with surface in-situ observations to 
follow crack initiation and propagation and DIC method was used to measure the mechanical fields. An etching method, which gives a natural texture to the aluminium dendrites by revealing segregation of Si, was developed to make DIC feasible to an acceptable resolution without adding a speckle pattern that will also mask the microstructure. The relations between cracks and strain localizations are observed for the validation in the tensile test and the application in LCF tests. Post-mortem analysis was performed using OM and SEM.

In LFC A319 alloy, the main mechanisms in low cycle fatigue were highlighted.

1. Large pores, especially for surface or near surface pores, play the most critical role for crack initiation. Crack initiation is ascribed to strain localizations induced by: (a) large pore; (b) the propagation of an already nucleated crack; (c) their coupling influence. A large number of surface or near surface large pores accelerates crack initiation and also reduces fatigue life. Indeed, porosity reduction is an industrial issue which may be difficult to attain. However, surface or near surface pores, which are the most critical, could be minimized by avoiding surface machining of components at least in the highly stressed areas of the component. Raw cast surfaces are generally free from defects.

2. Cracks propagated along hard inclusions while the orientation of hard inclusions has an influence on crack propagation: (a) When it is the same as the direction of crack propagation, the crack is prone to propagate along hard inclusions; (b) When it is perpendicular to the direction of crack propagation, the crack is arrested, then the arrested crack spends more cycles to continue to propagate by changing the direction of propagation to the direction along hard inclusions or by breaking hard inclusions to pass them. Considering this complex influence of hard inclusions on crack growth, more studies should be performed to study if the heat treatments that are used to modify hard inclusions morphology, e.g. Si modification, could help increase crack growth resistance.

\section{Acknowledgements}

This research work was funded by INDiANA-ANR project (grant ANR-12-RMNP-0011) and PSA Peugeot Citroën. The authors would like to thank TOMCAT beamline at Swiss Light Source (SLS) for providing SR-CT beamtime, and the China Scholarship Council (CSC) for funding the PhD thesis of Long WANG. 


\section{References}

1 Li Z, Limodin N, Tandjaoui A, Quaegebeur P, Witz J-F, Balloy D. In-situ 3D characterization of tensile damage mechanisms in A319 aluminium alloy using X-ray tomography and digital volume correlation. Mater Sci Eng A. 2020;794: 139920 .

2 Tabibian S, Charkaluk E, Constantinescu A, Szmytka F, Oudin A. TMF-LCF life assessment of a Lost Foam Casting A319 aluminum alloy. Int J Fatigue. 2013;53: 75-81.

3 Wang L. Influence of the Casting Microstructure on Damage Mechanisms in Al-Si Alloys by Using 2D and 3D in-Situ Analysis. PhD thesis, Ecole Centrale de Lille; 2015.

4 Zhang S, Wang Z, Han Y, Zheng Y, Zhang D. Experimental and theoretical studies on thermo-mechanical fatigue test for aluminium cast alloy. Fatigue Fract Eng Mater Struct. 2020;43: 110-118.

5 Tabibian S, Charkaluk E, Constantinescu A, Szmytka F, Oudin A. TMF criteria for Lost Foam Casting aluminum alloys. Fatigue Fract Eng Mater Struct. 2013;36: 349-360.

6 Li Z, Limodin N, Tandjaoui A, Quaegebeur P, Witz J-F, Balloy D. Influence of Fe content on the damage mechanism in A319 aluminum alloy: Tensile tests and digital image correlation. Eng Fract Mech. 2017;183: 94 108.

7 Dezecot S, Buffiere J-Y, Koster A, et al. In situ 3D characterization of high temperature fatigue damage mechanisms in a cast aluminum alloy using synchrotron X-ray tomography. Scr Mater. 2016;113: 254-258.

8 Ge B, Liu X, He G, Le P, Wen Z, Wang Q. Quantitative relationship between microstructure characteristics and fatigue parameters of A319 casting alloy. Fatigue Fract Eng Mater Struct. 2020;43: 605-616.

9 Niane NT, Michalet J-P. Validation of Foundry Process for Aluminum Parts with FLOW-3D Software. In: Flow Science. New York; 2011.

10 Geffroy P-M, Lakehal M, Goñi J, Beaugnon E, Heintz J-M, Silvain J-F. Thermal and mechanical behavior of AlSi alloy cast using magnetic molding and lost foam processes. Metall Mater Trans A. 2006;37: 441-447.

11 Tabibian S. Contributions to Thermomechanical Fatigue Criteria for Lost Foam Casting Aluminum Alloys. PhD thesis, Ecole Centrale de Lille; 2011.

12 Wang QG, Apelian D, Lados DA. Fatigue behavior of A356-T6 aluminum cast alloys. Part I. Effect of casting defects. J Light Met. 2001;1: 73-84.

13 Wang QG, Apelian D, Lados DA. Fatigue behavior of A356/357 aluminum cast alloys. Part II - Effect of microstructural constituents. J Light Met. 2001;1: 85-97.

14 Ammar HR, Samuel AM, Samuel FH. Porosity and the fatigue behavior of hypoeutectic and hypereutectic 
aluminum-silicon casting alloys. Int J Fatigue. 2008;30: 1024-1035.

15 Gall K, Horstemeyer M, McDowell DL, Fan J. Finite element analysis of the stress distributions near damaged Si particle clusters in cast Al-Si alloys. Mech Mater. 2000;32: 277-301.

16 Fan J, McDowell DL, Horstemeyer MF, Gall K. Cyclic plasticity at pores and inclusions in cast Al-Si alloys. Eng Fract Mech. 2003;70: 1281-1302.

17 Zhang H, Toda H, Hara H, et al. Three-Dimensional Visualization of the Interaction between Fatigue Crack and Micropores in an Aluminum Alloy Using Synchrotron X-Ray Microtomography. Metall Mater Trans A. 2007;38: $1774-1785$.

18 Stolarz J, Madelaine-Dupuich O, Magnin T. Microstructural factors of low cycle fatigue damage in two phase AlSi alloys. Mater Sci Eng A. 2001;299: 275-286.

19 Firouzdor V, Rajabi M, Nejati E, Khomamizadeh F. Effect of microstructural constituents on the thermal fatigue life of A319 aluminum alloy. Mater Sci Eng A. 2007;454-455: 528-535.

20 Arami H, Khalifehzadeh R, Akbari M, Khomamizadeh F. Microporosity control and thermal-fatigue resistance of A319 aluminum foundry alloy. Mater Sci Eng A. 2008;472: 107-114.

21 Wang L, Limodin N, El Bartali A, et al. Influence of pores on crack initiation in monotonic tensile and cyclic loadings in lost foam casting A319 alloy by using 3D in-situ analysis. Mater Sci Eng A. 2016;673: 362-372.

22 Wang L, Limodin N, El Bartali A, Witz J-F, Buffiere J-Y, Charkaluk E. Application of Synchrotron RadiationComputed Tomography In-Situ Observations and Digital Volume Correlation to Study Low-Cycle Fatigue Damage Micromechanisms in Lost Foam Casting A319 Alloy. Metall Mater Trans A. 2020;51: 3843-3857.

23 Boulos V, Fristot V, Houzet D, Salvo L, Lhuissier P. Investigating performance variations of an optimized GPUported granulometry algorithm. In: 2012 Conference on Design and Architectures for Signal and Image Processing (DASIP). ; 2012:1-6.

24 Gao YX, Yi JZ, Lee PD, Lindley TC. A micro-cell model of the effect of microstructure and defects on fatigue resistance in cast aluminum alloys. Acta Mater. 2004;52: 5435-5449.

25 Yi JZ, Gao YX, Lee PD, Flower HM, Lindley TC. Scatter in fatigue life due to effects of porosity in cast A356T6 aluminum-silicon alloys. Metall Mater Trans A. 2003;34: 1879-1890.

26 Image Stitching. ImageJ. Available at: https://imagej.net/Image_Stitching. Accessed September 7, 2020.

27 Haddadi H, Belhabib S. Use of rigid-body motion for the investigation and estimation of the measurement errors related to digital image correlation technique. Opt Lasers Eng. 2008;46: 185-196.

28 Vander GF. Color Metallography. In: Metallography and Microstructures. ASM International; 2004. 
29 Zwieg T. Specimen Preparation for High Edge Retention of Aluminum Alloys. Ind Heat Ind Heat. 2003;70: 4345.

30 Thévenaz P, Unser M. User-friendly semiautomated assembly of accurate image mosaics in microscopy. Microsc Res Tech. 2007;70: 135-146.

31 Klein S, Staring M, Murphy K, Viergever MA, Pluim JPW. elastix: a toolbox for intensity-based medical image registration. IEEE Trans Med Imaging. 2010;29: 196-205.

32 Rabinovich SG. Measurement Errors and Uncertainties. New York, NY: Springer New York; 2006.

33 Amiot F, Bornert M, Doumalin P, et al. Assessment of Digital Image Correlation Measurement Accuracy in the Ultimate Error Regime: Main Results of a Collaborative Benchmark. Strain. 2013;49: 483-496.

34 Limodin N, El Bartali A, Wang L, Lachambre J, Buffiere J-Y, Charkaluk E. Application of X-ray microtomography to study the influence of the casting microstructure upon the tensile behaviour of an Al-Si alloy. Nucl Instrum Methods Phys Res Sect B Beam Interact Mater At. 2014;324: 57-62.

35 Roux S, Hild F, Viot P, Bernard D. Three-dimensional image correlation from X-ray computed tomography of solid foam. Compos Part Appl Sci Manuf. 2008;39: 1253-1265.

36 Passieux J-C, Périé J-N. High resolution digital image correlation using proper generalized decomposition: PGDDIC. Int J Numer Methods Eng. 2012;92: 531-550.

37 Gomes Perini LA, Passieux J-C, Périé J-N. A Multigrid PGD-based Algorithm for Volumetric Displacement Fields Measurements. Strain. 2014;50: 355-367.

38 Schijve J, ed. Fatigue of Structures and Materials. Dordrecht: Springer Netherlands; 2009.

39 Verreman Y, Nie B. Short Crack Growth and Coalescence Along the Toe of a Manual Fillet Weld. Fatigue Fract Eng Mater Struct. 1991;14: 337-349.

40 Warmuzek M. Aluminum-Silicon Casting Alloys: Atlas of Microfractographs. illustrated edition edition. Materials Park, OH: ASM International; 2004.

41 Buffière J-Y, Savelli S, Jouneau PH, Maire E, Fougères R. Experimental study of porosity and its relation to fatigue mechanisms of model Al-Si7-Mg0.3 cast Al alloys. Mater Sci Eng A. 2001;316: 115-126.

42 Zeng L, Sakamoto J, Fujii A, Noguchi H. Role of eutectic silicon particles in fatigue crack initiation and propagation and fatigue strength characteristics of cast aluminum alloy A356. Eng Fract Mech. 2014;115: 1-12.

43 Starink MJ. Reduced fracturing of intermetallic particles during crack propagation in age hardening Al-based alloys due to PFZs. Mater Sci Eng A. 2005;390: 260-264. 